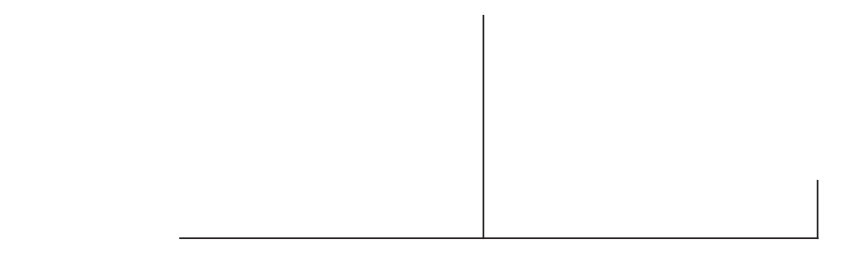

Rev. Latinoam. Psicopat. Fund., II, 2, 159-176

\title{
Investigação psicanalítica e terapia do grupo de neuroses limítrofes ${ }^{1,2}$
}

\author{
Adolf Stern
}

\begin{abstract}
I
Sabe-se que uma ampla gama de pacientes não cabe nitidamente no grupo dos psicóticos nem no dos psiconeuróticos e que é muito complexo lidar eficientemente com esse grupo limítrofe de pacientes, independentemente do método psicoterapêutico escolhido. O que chamou minha atenção há uns três ou quatro anos, foi o aumento do número desses pacientes que buscam um tratamento. Não costumava tratá-los de modo analítico, salvo se apresentassem sintomas neuróticos agudos (p. ex. ansiedade, depressão etc.) e se precisassem de terapia imediata. Com estes, tentei a terapia analítica habitual embora tivesse de parar, na grande maioria dos casos, após um tempo mais ou menos longo de tratamento, sem ter-lhes trazido muita melhora. No caso do "caráter neurótico", que constitui a maior parte desse grupo limítrofe, não tentei, na maioria das vezes, qualquer forma de tratamento, dado que minha experiência indica
\end{abstract}

1. A. Stern. "Psychoanalitic investigation of and the therapy in the borderline group of neuroses”, The Psychoanalytic Quarterly, vol. 7, 1938, pp. 467-489.

2. Tradução de Alain François e revisão técnica do Prof. Dr. Mário Eduardo Costa Pereira (Laboratório de Psicopatologia Fundamental-UNICAMP) 


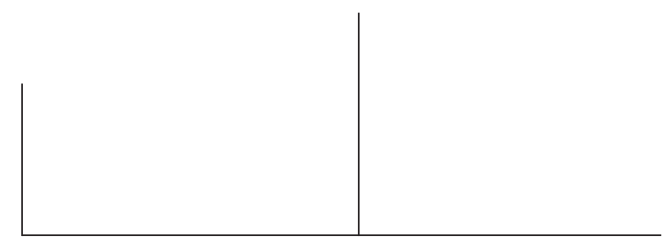

que nosso conhecimento da terapia analítica como vem sendo usada em pacientes psiconeuróticos não basta para chegar a bons resultados nesse grupo, especialmente quando seus sofrimentos não são agudos o suficiente para justificar uma terapia imediata.

Nos últimos três ou quatro anos, o número desses pacientes aumentou; via de regra, aceitei cuidar apenas de doentes agudos que precisavam de tratamento. Fracassos sucessivos no passado ensinaram-me que nosso conhecimento não é suficiente para tratar dessas pessoas. O inevitável ocorria: ficou claro para mim que embora tivesse tratado de modo suficientemente completo os fenômenos de libido objetal, esses pacientes continuavam doentes, ao passo que psiconeuróticos francos tratados do mesmo modo reagiam bem. Passei, então, a estudar esses pacientes mais em detalhe para ver quais aspectos do quadro clínico não eram afetados por métodos que funcionam no tipo comum dos psiconeuróticos. Proponho meus resultados nas páginas abaixo.

Esse grupo limítrofe de pacientes apresenta um quadro de sintomas clínicos razoavelmente bem definidos. Isso facilita sua apresentação sob duas perspectivas: a primeira linha de abordagem é histórica, tal como trazida pelos pacientes e desenvolvida no decorrer do tratamento. A segunda linha de abordagem, para tentar entender esse grupo limítrofe de pacientes, busca investigar os acontecimentos na situação de transferência; aqui, encontramos fenômenos patognômicos, que se revelaram diferentes dos mesmos fenômenos em situações de transferência no tipo comum de pacientes neuróticos.

Os sintomas clínicos que enumero e descrevo a seguir cabem nas categorias de formações reativas ou de traço de caráter. Embora apenas alguns sejam específicos do grupo limítrofe, outros são mais acentuados, constantes e difíceis de tratar por meio da terapia psicanalítica do que no caso das psiconeuroses. São eles:

- Narcisismo;

- "Sangramento" psíquico;

- Hiper-sensibilidade desmedida;

- Rigidez psíquica e corporal - "Personalidade rígida”;

- Reações terapêuticas negativas;

- O que parece com sentimentos de inferioridade constitucionalmente arraigados, profundamente embutidos na personalidade do paciente;

- Masoquismo;

- O que pode ser descrito como um estado de insegurança ou ansiedade orgânica profunda;

- O recurso a mecanismos de projeção;

- Dificuldades em testar a realidade, particularmente nas relações pessoais. 
Parece-me do conhecimento geral o fato de que esse grupo limítrofe pertence essencialmente às neuroses ou caracteres narcísicos. Meus pacientes, como mencionado acima, constituem um amplo grupo indefinido entre psicoses e neuroses de transferência, compartilhando características de ambas, embora mostrem inclinações nítidas para a psicose; lembro que costumamos chamar certas psicoses de "neuroses narcísicas". Esse grupo limítrofe revela a presença de narcisismo num grau inexistente no tipo comum de pacientes neuróticos. Seu quadro clínico inteiro fundamenta-se no narcisismo. Nas neuroses, costumamos procurar as causas primárias nos transtornos aos quais a sexualidade infantil foi exposta.

Com isso na cabeça, uma investigação dos períodos narcísicos na infância mais remota desses pacientes revela fatores que afetam seu desenvolvimento narcísico de modo adverso. Em pelo menos $75 \%$ dos casos desse grupo, os históricos mostram que um ou mais dos seguintes fatores estiveram presentes desde a mais tenra infância. A mãe era uma neurótica ou psicótica franca, que desenvolveu uma psicose ou vários episódios psicóticos de curta duração em mais de uma oportunidade. Essas mães ocasionaram mágoas em seus filhos por causa de uma deficiência de afecção materna espontânea: entre elas estavam mães que se mostravam excessivamente preocupadas ou zelosas; eram muito meticulosas quanto aos hábitos, comida e comportamento das crianças, embora lhes faltasse a capacidade sadia de afecção espontânea. Houve, na família, brigas que se estenderam por muitos anos entre os pais e muitas explosões temperamentais entre eles ou para com a criança. Em algumas famílias, houve divórcio, separação e em um dos casos abandono do lar por um dos cônjuges, antes dos pacientes chegarem aos sete anos, o que contribuiu como fontes suplementares de forte insegurança numa época em que essas crianças já se encontravam num estado de privação afetiva devido à discórdia entre os pais antes da separação se efetivar. Todos meus pacientes ficaram com as próprias mães, embora estas não sejam realmente adequadas do ponto de vista de sua capacidade em sentir afecção simples e espontânea para com eles. Outros fatores encontrados nesses pacientes são brutalidade, negligência e até mesmo crueldade por parte desses pais durante muitos anos. Esses fatores operam de modo mais ou menos constante durante vários anos desde a mais tenra infância e não são experiências únicas.

Um breve olhar no histórico do tipo geral de pacientes neuróticos nos mostra que tais dados raramente desempenham um papel tão importante. Nossos pacientes sofrem, no campo psíquico, do que o Dr. David M. Levy chamou de "carência afetiva”, assim como as deficiências alimentares deixam marcas de carência física, isto é, transtornos nutricionais. Em razão dessas experiências, nosso grupo nunca desenvolve um senso de segurança, o qual se adquire pelo fato de ser amado, direito 


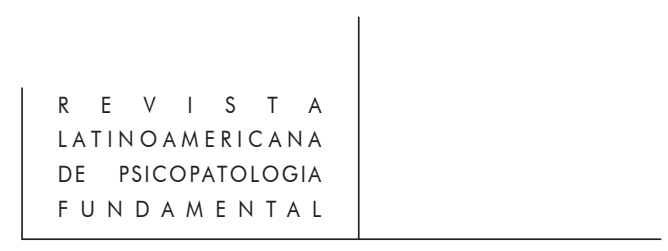

natural de toda criança. Esses pacientes sofrem de desnutrição (narcísica) afetiva. Ao se estabelecer essa relação, no entanto, cabe se indagar até que ponto uma constituição ou dotação peculiar ou o meio em si, ou ainda uma combinação de ambos influi no quadro clínico. Não tenho resposta para essa pergunta.

O quadro clínico se desenvolve na base de um narcisismo ferido, carente. Nem as gratificações narcísicas normais nem as necessidades normais de autopreservação na esfera psíquica estão suficientemente presentes. As raízes dos traços de caráter neuróticos e, em alguns pacientes, também dos transtornos neuróticos, têm raízes profundas nesses períodos remotos de carência psíquica e insegurança devidos à falta de afecção parental, principalmente materna. Pode-se, portanto, inferir que um transtorno no desenvolvimento narcísico em crianças muito jovens é responsável pelos traços de caráter neuróticos, ou transtornos neuróticos, nesse grupo, assim como os transtornos no desenvolvimento sexual (amor objetal) está na base dos transtornos psiconeuróticos.

Como afirma Freud, toda formação de sintomas neuróticos é uma tentativa, por parte do ego, de minimizar ou eliminar o desamparo intolerável produzido pela ansiedade. No grupo psiconeurótico, a ansiedade se desenvolve na base dos impulsos sexuais infantis; em nosso grupo, geralmente, na base dos impulsos narcísicos infantis. O narcisismo está presente no grupo limítrofe como componente de caráter subjacente. É o terreno no qual os fenômenos descritos mais adiante têm sua origem, do qual dependem no que diz respeito às suas formas e às funções que cumprem. Lembrando que a ansiedade é o motor da defesa na formação de traços de caráter e nos sintomas neuróticos, descreverei em detalhe os traços de caráter acima mencionados como se apresentam no grupo limítrofe.

\section{“Sangramento" psíquico}

O quadro de um "hemorrágico” psíquico é familiar. Em vez de uma reação de resistência a uma experiência traumática ou dolorosa, o paciente "entrega os pontos”, se assim posso dizer, e está a um passo da morte. Fica imóvel, letárgico em vez de agir, desaba em vez de lutar: trata-se de uma espécie de fingir-se morto. Nessa tranqüilidade o paciente está reflexivamente num estado de autoproteção que requer um mínimo de ação, e exibe uma relaxação completa para contrabalançar as fortes exigências do perigo sobre o organismo. Paralisia em vez de saída ou luta, tal é a reação. $\mathrm{O}$ estado de desabamento representa, num certo sentido, uma defesa reflexa na forma de preparação para a recuperação. 
Hiper-sensibilidade desmedida

A rigor, a hiper-sensibilidade psíquica pode ser comparada à hiper-sensibilidade física de crianças muito jovens, causada por estímulos sensoriais físicos. Está muito claro que essa hiper-sensibilidade serve de maneira reflexa, automática, como um aparato ou instrumento receptivo refinado para melhor detectar os perigos e tomar as precauções apropriadas. Como todos os outros sintomas neuróticos, este não tem a menor função de realidade. Do ponto de vista neurótico do paciente, no entanto, a hiper-sensibilidade é um sintoma lógico ou um traço de caráter. De acordo com uma insegurança profundamente arraigada, que requer uma cautela e uma consciência indevidas do perigo, trata-se claramente de uma vantagem, como qualquer outro sintoma neurótico. Em muitos pacientes, essa hiper-sensibilidade se aproxima do mecanismo pelo qual o paranóico desenvolve suas idéias de referência. Meus pacientes sentem-se constantemente insultados e feridos por reflexões insignificantes feitas por pessoas com as quais se relacionam e desenvolvem ocasionalmente idéias ligeiramente paranóicas.

\section{Rigidez psíquica - "Personalidade rígida”}

Este é um dos mecanismo mais fascinantes de se investigar, ver operar e resolver. Pois pode-se modificar uma "personalidade rígida" por meio dos métodos psicanalíticos. Se não esquecermos que a ansiedade é o motor que estimula a ação do ego em sua própria defesa, a personalidade rígida torna-se compreensível. Além do mais, como disse antes, e repetirei quando discutirmos os fenômenos de transferência, as reações de defesa desse grupo limítrofe de paciente são quase sempre de natureza reflexa. O corpo é levado a uma atitude de comportamento protetor por causa de uma ansiedade que se origina num perigo quer externo quer interno. Nas neuroses de transferência, em compensação, os mecanismos de defesa têm explicações e valores psicológicos muito mais amplos. Ao avaliar a importância da personalidade rígida, sempre guardo em mente, como ponto de referência, o abdome rígido ou o joelho rígido como respostas reflexas a uma inflamação nessas respectivas regiões. Uma imagem extrema, mais uma vez apenas a título de comparação, é a catatonia rígida. Se considerarmos os olhos sempre em movimento, atentos, alertas, e a imagem rígida do corpo, uma relação entre ambas, com base na proteção contra o perigo, torna-se bastante clara. Nos pacientes considerados, a rigidez psíquica e com certa freqüência uma rigidez física, são fenômenos de natureza protetora e reflexa sempre presentes.

O que não ficou muito claro para mim é a época em que tais fenômenos surgem. Em alguns pacientes, parece que a rigidez se manifesta antes dos quatro ou cinco anos, intensifica-se nos períodos cruciais como, por exemplo, a puberdade 


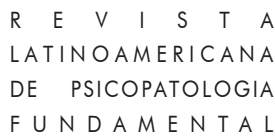

ou experiências importantes (para a produção de ansiedade do paciente). O amadurecimento desses pacientes está ladeado por grandes perigos (ansiedade) contra os quais se eleva rapidamente uma proteção por meio da rigidez psíquica ou física. O reconhecimento das metas defensivas dessa rigidez fornece a chave para seu tratamento terapêutico, assim como quando se quer lidar com as defesas no grupo de neuroses de transferência.

\section{Reações terapêuticas negativas}

Esses fenômenos são observados com certa regularidade nesse grupo de pacientes. Começam a surgir depressão, raiva repentina, desânimo e ansiedade como respostas a qualquer interpretação envolvendo feridas do amor-próprio. Uma vez que se lida com a ansiedade essencialmente pelas medidas defensivas, torna-se bastante claro que toda interpretação que comprometa a defesa neurótica libera também a ansiedade que levara o paciente a recorrer aos mecanismos protetores para encontrar um sentimento de segurança, o que acarreta depressão, desânimo ou raiva. A margem de segurança desses pacientes é extremamente estreita e uma interpretação esclarecedora os lança, ao menos por um momento, num desânimo, de modo que é raro notar uma reação favorável às descobertas. Além do mais, ao avaliar a importância da reação terapêutica negativa, não se pode esquecer que a forte imaturidade desses pacientes, bem como seu narcisismo inseguro, diluído, leva-os a reagir às interpretações como provas de falta de apreço ou de amor por parte do analista. Com esses pacientes, a terapia analítica é como uma operação cirúrgica, a qual é uma medida terapêutica traumática em sua essência, porém necessária.

Todos os cuidados devem ser tomados para que a técnica operativa seja adaptada ao paciente considerado no dado momento e não à doença. Uma boa avaliação baseada na experiência clínica tem um valor inestimável nesse caso. Uma reação terapêutica negativa é, no entanto, inevitável; em certos pacientes, a reação é extremamente desfavorável e pode até se tornar perigosa; certos pacientes podem desenvolver depressões, idéias suicidas ou fazer tentativas de suicídio. Nesses estados terapêuticos negativos as atitudes necessariamente dependentes são exageradas e torna-se extremamente difícil lidar com os pedidos de piedade, simpatia, afecção e proteção dirigidos ao analista; a situação de transferência torna-se mais complicada ainda do que já é por natureza. Geralmente, o relacionamento desses pacientes com pessoas em posição de autoridade é determinado por suas necessidades de amor e proteção, que eles esperam ganhar por meio de métodos infantis, especialmente obediência, complacência e pedidos insistentes por tratos gentis e meigos. As mesmas atitudes imperam na situação de transferência e os pacientes, embora entendam as interpretações, reagem ao mesmo tempo de modo 
neurótico (p. ex., por meio de reações terapêuticas negativas) como se se sentissem rejeitados. O resultado é um aumento da dependência para com o analista enquanto figura parental.

\section{Sentimentos de inferioridade}

Tal como para os outros fenômenos mencionados, não tentarei encontrar uma explicação da origem deste. Meu objetivo é mostrar sua função clínica como uma parte lógica da patologia da doença (caráter neurótico) e demonstrar aqui também que um sintoma é uma prova de que parte do organismo, o ego, está empenhada em combater a ansiedade. Nesses pacientes, os sentimentos de inferioridade são invasores e abrangem quase toda a personalidade. Geralmente, esses sentimentos são percebidos pelos pacientes como desagradáveis, embora lógicos e inevitáveis. Eles não questionam a validade do próprio julgamento a esse respeito. Tem-se, aliás, a impressão de uma tonalidade delirante. Os pacientes estão convencidos de sua inferioridade e falta-lhes toda e qualquer perspicácia quanto à natureza sintomática desses sentimentos. Muitos de meus pacientes tiveram sucesso no seu campo de atuação, adquiriram uma excelente educação geral e profissional; muitos exibem características físicas e psicológicas agradáveis - mas nenhuma dessas realizações, nem o seu conjunto, têm a menor influência sobre o fato de se julgarem pessoas inferiores. Uma imagem próxima a esse quadro é a autodepreciação delirante dos melancólicos.

Esses pacientes limítrofes são casos de desenvolvimento interrompido e manifestam traços de caráter infantis. Desse ponto de vista, como tentarei mostrar com alguns fenômenos de transferência, é muito lógico que a partir dessas premissas os pacientes se sintam inferiores - imaturos, jovens, fracos, tímidos, indignos, nunca amados etc. Esses sentimentos de inferioridade jogam em favor da ansiedade dominante quando uma ação ou um pensamento, podendo envolver um comportamento adulto, são exigidos deles. A discrepância entre o que consideram ser um comportamento adulto e o que se sentem capazes de fazer basta para desencadear a ansiedade suficiente para que recuem e mergulhem na inação, com uma consciência aguda, nessas horas, de seus sentimentos de inferioridade. Encontram a segurança contra a recorrência da ansiedade, embora de modo insatisfatório para a parte saudável do julgamento do paciente, permanecendo inativos e afirmando sua inferioridade, na esperança de que, em vez de serem empurrados para um comportamento adulto, viraram alvos de comiseração e serão consolados ou autorizados a permanecer dormentes. A convicção de que é inferior leva o paciente a um comportamento inativo e é constantemente afirmada ao analista (figura paterna) para conseguir os mesmos objetivos (fazer surgir o papel parental). É entre esses pacientes que encontramos com freqüência (a praga na vida de um analista) 


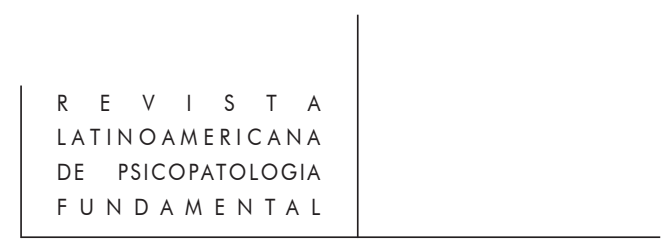

aqueles que juntaram uma educação psicanalítica completa por terem sido analisados e continuarem bastante doentes. Têm qualidades intelectuais para acumular conhecimentos e, a menos que o analista esteja alerta, não vão usá-los para encontrar as fontes de seus sentimentos de inferioridade, mas, antes, para inchar seu ego com resultados pseudoterapêuticos.

\section{Masoquismo}

Não está muito claro como isso pode ser um fenômeno defensivo, de correção e proteção. Sua presença é clara o suficiente e facilmente verificada. Nesse tipo de pacientes, a autopiedade e a autocomiseração, a apresentação de uma imagem desesperada de pessoa ferida, com longos sofrimentos, são regularmente encontradas, bem como o que chamo de "lamber as chagas", uma tendência a se entregar à autopiedade. Essas manifestações podem, grosseira embora não muito claramente, ser consideradas agentes visando compensar aquilo que os pacientes vêem, em alguns casos até com justeza, como falta de amor em sua juventude, uma espécie de apelo tácito por ajuda e amor como faria uma criança carente. Não resta dúvida de que esses pacientes sofrem muito. Muitos pendem em direção à depressão e alguns de meus pacientes nesse grupo tiveram até depressões agudas, e o masoquismo é uma ocorrência muito freqüente. Isso fica patente em seus sonhos, sintomas e vida. Eles se magoam em todas as suas relações de negócios, profissionais, sociais, ou seja, em todas as relações afetivas.

O masoquismo em si é um fenômeno tão maligno que parece fútil ver na sua presença constante nesses pacientes um propósito curativo ou defensivo. No que diz respeito aos outros traços de caráter, é comparativamente mais fácil encontrar esse propósito.

\section{Insegurança ou ansiedade "somática"}

Num certo sentido, usar a palavra ansiedade para esse sintoma clínico particular é inadequado pelas simples razão de que a ansiedade não é um fenômeno constante e que não há queixas regulares, por parte dos pacientes, contra sua presença. Pelo contrário, muitos apresentam à observação imediata uma equanimidade mental e física plácida, ou, melhor dizendo, impassível. Impressionam os observadores por não se perturbarem o suficiente em situações difíceis. No decorrer de sua investigação analítica torna-se aparente que um sistema de defesas desmedidamente adequado se estabeleceu e ajuda a manter essa pseudo-equanimidade. Quando o analista sabe disso, tanto ele como o paciente saem beneficiados. Isso deveria guiar o procedimento visando desfazer o quanto for possível das defesas do paciente 
por vez. Pois esses pacientes são capazes de liberar quantidades de ansiedade desagradáveis e até perigosas durante sua análise terapêutica de modo que, à medida que o analista insiste em seus esforços simultâneos de investigação e terapia, ele se torna familiar com esse elaborado sistema de defesa. Com o tratamento, uma imagem mais clara de uma insegurança profundamente subjacente se revela, a qual remonta à mais tenra infância, com raízes penetrando em períodos além da memória. Em vez da imagem clínica razoavelmente comum de experiências traumáticas na infância, que nossos pacientes neuróticos tornam mais ou menos familiar, parece que a ansiedade sempre existiu ou foi dissipada por alguma coisa. Raramente nos dão a impressão de terem sentido, em qualquer momento de sua vida, segurança ou autoconfiança, a não ser a conferida pelo meio, de alguma maneira, no instante vivido, quando recebem assentimento, ou, ainda, quando alguma experiência lhes transmitiu um sentimento temporário de estarem completamente adequados. Sua autoconfiança geralmente constitui uma experiência evanescente, nunca algo obtido através de um processo de crescimento, maturidade, experiência, teste de realidade. Isto é, em um indivíduo com autoconfiança normal, uma experiência infeliz ou estúpida é tida como uma coisa em si, à qual reage em conseqüência. Para um indivíduo do nosso grupo, uma dessas experiências é interpretada para significar que ele é extremamente azarado ou estúpido e que sofre de uma depreciação total de seu ego (amor-próprio) ou, pelo contrário, uma experiência feliz vai provocar uma exaltação ou um amor-próprio exagerados. Esses indivíduos reagem segundo a fórmula "tudo ou nada". É em relação com essa profunda insegurança que o amor parental primário parece desempenhar um papel importante. Quem trabalha com crianças pode comprovar diretamente essas afirmações a respeito de adultos. Gostaria de mencionar que meu interesse para as causas possíveis desses fenômenos nos adultos surgiu da leitura dos trabalhos do Dr. David M. Levy sobre o assunto e de conversas com ele. Com base na observação, parece interessante não esquecer que um sentido de segurança, de autoconfiança, nas crianças, se fundamenta essencialmente na afecção espontânea materna, e, em grau menor, paterna. Essas crianças privadas de algo tão essencial para um narcisismo psíquico adequado, como comida para o corpo, irão enfrentar experiências na sua vida posterior já com o fardo da insegurança patológica, isto é, apresentarão uma tendência a desenvolver ansiedade. As experiências sexuais, ou qualquer coisa que, em sua opinião, seja condenado por autoridades, ou que possa envolver perigo ou constituir uma provação para eles, será abordada desse jeito particular, porém lógico aos seus olhos. Por causa do que vêem como seu estado precário, grandes quantidades de ansiedade estão sempre prestes a ser mobilizadas, um vez que o perigo e a reprovação ameaçam tornar sua posição ainda mais precária. Reações de defesa, particularmente as descritas acima, entram em jogo. Esses adultos, via de regra, foram crianças desmedidamente submissas e obedientes por causa de seu medo ou necessidade. 


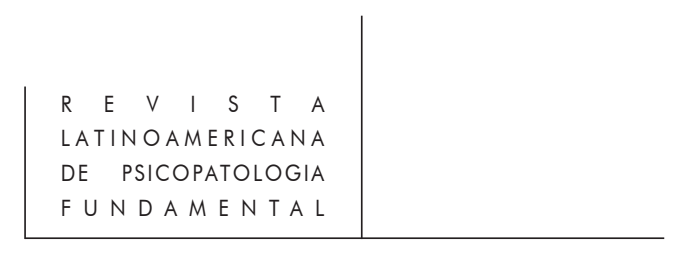

Eles se agarraram a pais ou substitutos com o desespero de quem está ameaçado por graves perigos. A inveja do pênis na menina, e a ansiedade da castração, no menino, desempenham um papel considerável. A ansiedade causada por impulsos sexuais também tem seu papel importante, assim como, sem dúvida, o complexo de Édipo. Mas no tocante a esses fatos, não se pode esquecer que, antes disso, ou concomitantemente a isso, existe um grau de imaturidade e de insegurança que não está presente nas neuroses de transferência comuns com as quais somos familiarizados e que essa insegurança profunda brota dos transtornos das necessidades narcísicas.

\section{O recurso a mecanismos de projeção}

O recurso comum a mecanismos de projeção nas psicoses é conhecido de todos. Isso ocorre muito em nossos pacientes e parece ser o fenômeno que liga esse grupo ao dos psicóticos. O recurso a esses mecanismos implica a existência de uma parte defeituosa no julgamento que confira ao ego do paciente uma maneira mais fácil de lidar com sua ansiedade neurótica. As causas de sua ansiedade são projetadas no mundo externo; o comportamento defensivo instala-se à custa do insight. O paciente imaturo, narcisicamente carente, pode então proteger-se mais facilmente do que considera ser um meio hostil, por meio de medidas defensivas (personalidade rígida, introversão, retraimento físico ou psíquico, sistemas ligeiramente delirantes etc.). Ele é, entretanto, incapaz de reconhecer que sua ansiedade vem de dentro, uma vez que isso exigiria mudanças em direção à maturidade e à autoconfiança que ele não consegue alcançar. O melhor caminho é explicar suas dificuldades com base na atitude hostil do meio para consigo mesmo e as dificuldades desmedidas que sua concepção da realidade apresenta, especialmente no seu relacionamento com as pessoas, mais ainda pessoas em posição de autoridade.

\section{Dificuldades em testar a realidade}

A descrição desse item está na parte II, em relação ao tratamento das situações de transferência.

O desenvolvimento da doença, tal como se manifesta no decorrer da transferência, oferece uma oportunidade única de avaliar as diferenças entre o quadro clínico desse grupo limítrofe e o quadro das psiconeuroses francas. Tentei mostrar, na 
parte I deste trabalho, o papel muito importante desempenhado pelo narcisismo enquanto fator etiológico nesse grupo limítrofe: esse fator causal opera necessariamente no quadro clínico, tanto pela sua presença no paciente por ocasião da primeira consulta, como quando este o despeja no desenrolar da relação de transferência.

Por causa da influência preponderante do narcisismo no quadro clínico, o tratamento terapêutico do impulso narcísico patologicamente afetado surge como um problema que não tem tanta presença nas neuroses de transferência. Por conta disso, um procedimento lógico leva a algumas modificações da técnica psicanalítica.

Não esqueçamos o quadro genérico apresentado na parte I. Nesse grupo, como no de transferência, a prevenção da ansiedade é o motor do comportamento neurótico. Todos sabem que a situação de transferência é uma miniatura de neurose. Os mecanismos particulares usados pelo paciente para lidar com a ansiedade que emerge da situação de transferência nos oferecem uma pista para o diagnóstico e o prognóstico, de modo que ao observar o desenvolvimento do fenômeno de transferência estamos em posição de avaliar onde estamos e o que precisamos fazer.

Ao estudar a relação de transferência nesse grupo, vimos primeiro, e essencialmente, se estabelecer uma relação de extrema dependência para com o analista. Essas pessoas afetivamente imaturas não conseguem estabelecer uma relação afetiva a não ser nessa base. Sendo a necessidade de proteção muito grande, notamos nesses pacientes, como prova de dependência, um respeito estrito às regras, uma obediência, às vezes como que uma aplicação compulsiva no trabalho psicanalítico e esforços para conseguir assentimento, elogios, uma ênfase no transtorno e no sofrimento para despertar a simpatia protetora do analista. Esse apego pode-se transformar num envolvimento afetivo tão intenso que os cuidados com esse aspecto da relação de transferência consomem uma quantia desmedida de tempo, muito maior do que no trabalho com pacientes menos imaturos.

Essa fase da relação de transferência nos dá um insight do grau de imaturidade do paciente. É impressionante descobrir, às vezes, a ingenuidade com a qual o analista é visto e aceito como um deus e um mágico pessoal. Alguns pacientes aceitam o analista como uma espécie de presença vaga, sem forma definida, que não deve nem ser olhada, sem a menor surpresa ou sentimento de irrealidade. $\mathrm{O}$ mais impressionante não é tanto a existência desses fenômenos, mas o fato de os pacientes não perceberem que é algo estranho, esquisito em sua psicologia, que torna tais atitudes possíveis. Eles aceitam o tamanho gigantesco, a onipotência e onisciência do analista como crianças acreditam em contas de fada ou na onipotência e onisciência de seus pais ou de Deus. Esses pacientes não conseguem nem esperam ajuda, amor ou cuidados (isto é "cura”) de ninguém que não reproduza, em sua fantasia, a figura parental em todas as proporções exageradas da infância. Quando esses pacientes desenvolvem ansiedade na situação analítica por causa de algo que perturbe esse estado de proteção positivo, essa ansiedade é grande, diretamente 


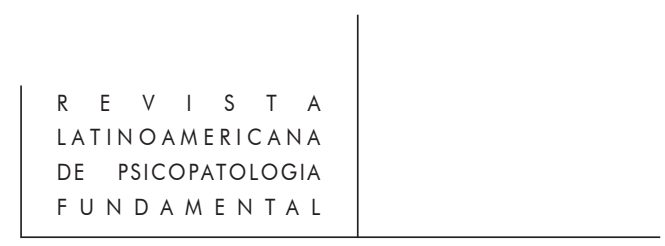

proporcional à proteção destruída ou ameaçada. Alguns pacientes sem a menor perspicácia afirmam sentir-se tão seguros e felizes durante a análise quanto no Nirvana. São simplesmente felizes. Pode-se vislumbrar a ansiedade, a depressão e raiva defensiva assim que o objeto dando amor, ingenuamente aceito, se torna hostil aos olhos do paciente. Quando esse agradável estado de Nirvana muda, surge uma confusão mental relativamente bem marcada e esforços dirigidos pela ansiedade para reconstruir a antiga realidade. Em tais estados, o trabalho analítico pouco tem a fazer. Os pacientes precisam ser acalmados e os esforços devem se concentrar em explicar essas mudanças em seu humor.

Alguns desses pacientes aproximam-se perigosamente de estados psicóticos nessas fases de sua transferência. Via de regra, nesse estado, os pacientes fazem esforços violentos para retornar à boa velha ilusão beatífica. Muitas vezes tentam, produzindo material analítico (associação e interpretações ou pela ênfase em seus sofrimentos), atenuar o que consideram e sentem como uma atitude cruel do analista. O distúrbio do senso da realidade, até onde o papel do analista está em jogo, é impressionante, mais particularmente porque os pacientes aceitam as implicações inconscientes do relacionamento como se fossem a realidade. De modo bastante interessante, nos estados de transferência ligeiramente perturbados, os pacientes sentem-se com freqüência desamparados apenas durante a sessão analítica. Muitos afirmam que assim que entram na sala de espera e, às vezes, até no próprio prédio, uma sensação aguda, aflitiva de ansiedade toma conta deles. Nenhum, que eu me lembre, comentou essa mudança como algo que não conseguisse explicar, mas, antes, aceitam-na como algo plenamente condizente com sua relação para com o analista. Como disse um deles: "O que mais poderia sentir que não esse misto de medo e de respeito".

Voltando ao assunto dos traços de caráter neuróticos (o décimo item de nossa lista, na parte I), a perturbação do senso de realidade é um fenômeno característico nesses pacientes em sua relação com o papel parental (imago) do analista. Mais uma vez não ocorre a esses pacientes que estão atribuindo proporções gigantescas a essa imago psíquica e física. A aceitação ingênua disso é algo notável; pode muito bem ser um aviso para que o analista observe cuidadosamente os efeitos, sobre seus pacientes, do que fala. Para estes, é um deus, um mágico, um oráculo quem fala, e isso com toda a força que caracteriza esses entes para os mais jovens; quando o paciente sente que esses seres estão favoravelmente inclinados a ele, a influência da informação trazida por essas imagos sobre o paciente é notável. Um tal processo, assim como um pensamento lógico a respeito da realidade, não devem ser esperados em nossas circunstâncias. O senso comum sadio e o teste da realidade estão suspenso, no paciente, ou deveriam estar. Do mesmo modo, quando essas imagos parecem hostil ao paciente, fica bem claro que qualquer coisa com sabor de crítica, como qualquer interpretação terá o mais perturbador efeito. Melhoras ilusórias são 
um fenômeno comum durante a transferência positiva. O aumento do amor-próprio para o que o paciente interpreta como assentimento, elogios ou preferência por ele da parte da imago é realmente nítido; tem a mesma intensidade que a autodepreciação produzida pelo que o paciente interpreta como críticas por parte da imago. A imaturidade afetiva desses pacientes impede uma transferência que acarrete consigo uma relação à realidade suficiente para dar ao analista um sentimento de segurança permitindo-lhe contar, em grande parte, com a habilidade do paciente em usar unicamente a pequena fração de inteligência que normalmente opera mais ou menos completamente durante as atividades profissionais deste. Com esses pacientes, muito mais do que com os neuróticos de transferência francos, é preciso ter cuidado com os efeitos do que o analista diz ao paciente. Pois é a imago que há muito opera na psique do paciente e não mais o analista como pessoa da realidade. Sabe-se que, no início do tratamento, distorções tão extremas da personalidade e das funções do analista são fenômenos característicos da e esperados na transferência. O que parece melhoras pode então ser melhor avaliado e decepções tristes por parte do analista e depressões por parte do paciente poderão ser evitadas.

A reação terapêutica negativa é um fenômeno constante nesses pacientes e constitui um sintoma clínico muito mais desconcertante e importante do que nos tipos comuns de pacientes. Gostaria de acrescentar algumas observações quanto ao que já foi escrito a respeito da reação terapêutica negativa em função de sua ocorrência na e sob a influência da transferência. Como se sabe, temos expectativas e presumimos que um paciente reagirá de modo favorável a toda descoberta feita para ele ou por ele no decorrer do trabalho analítico. No entanto, estas expectativas são justificadas? Quando da descoberta, certamente não. A reação terapêutica negativa só toma sua importância mais tarde, nesses pacientes, quando ocorrer uma reação de depressão, raiva, ansiedade ou desânimo, relacionada com essa mesma novidade ou interpretação. Isto quer dizer que, enquanto alguma familiaridade com o material desagradável deveria ter acontecido por causa da reiteração e resultado em alguma aceitação, os pacientes reagem por muito tempo como se fosse, de novo, tudo a mesma coisa. Parece-me que baseado nas premissas desses pacientes, essas reações são de se esperar, pois a reação terapêutica negativa significa que o incidente com ansiedade por enfrentar uma nova situação de perigo fora evitado à custa da dor, i.e.da depressão. Admitir algum conceito doloroso na consciência é algo repleto de ansiedade. Essa ansiedade é o que o paciente há de evitar; uma evitação bemsucedida confirma-se por uma reação terapêutica negativa.

Nesses pacientes, o processo de crescimento é norteado pela ansiedade. Ser maduro, para eles, especialmente em suas relações com as pessoas, é uma fantasia de perfeição tal como a que atribuem aos adultos. Pode ser alcançado em fantasia, mas o comportamento para comprová-lo ou testá-lo é norteado pela ansiedade. Quando alcança o estado de adulto com êxito, o paciente tem uma idéia secreta de 


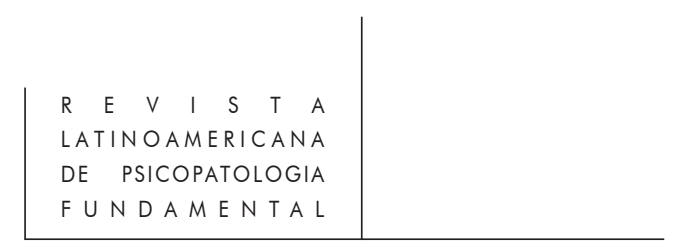

que seu feito não foi real e que ele pode facilmente ser desmascarado como um faz-de-conta. Ter êxito nesse feito significa para ele uma repressão bastante violenta de suas inferioridades neuróticas e um assumir (o que pode ser detectado) o papel de alguma das imagos tão invejada (pai, mãe). Os pacientes reconhecem corretamente nisso um certo faz-de-conta, embora muito impreciso e insuficiente demais para poder lhes servir.

A situação de transferência oferece oportunidades para se estudar isso: no cerne dessa situação está a gigantesca e excessiva avaliação da imago pelo paciente. O paciente não consegue identificar-se com o analista (imago), a não ser por meio da ilusão, isto é, o paciente nunca se identifica com o analista, mas com a concepção que se faz dele - por meio de um processo de projeção de seu próprio ideal de ego como incorporado no tamanho gigantesco do analista (imago). É esta figura que fala com ele. Portanto, quando, por exemplo, diz-se ao paciente que o que ele acabou de dizer indica alguma hostilidade reprimida, na infância, contra um irmão mais velho ou o pai, o paciente desaba por causa do medo do castigo por ter sido descoberto. É mais ou menos isso que tal interpretação significa para o paciente. O paciente muitas vezes promete se livrar dessa hostilidade assim que possível e pode retornar à próxima sessão relativamente satisfeito consigo mesmo e afirmar ao analista, na esperança de ser confortado, que conseguiu dominar e se livrar de seu ódio. Geralmente, esse mesmo material volta em pouco tempo, e propicia a mesma interpretação. A reação é semelhante à primeira - pesar, culpa, medo de castigo, medo de ser reprovado, todos são mobilizados de novo, uma vez que a maior parte da "visão" foi ilusória, em razão do esforço para ganhar o assentimento do analista e reforçar o amor-próprio e a autoconfiança dos pacientes.

Outra fase dessa reação terapêutica negativa é a que pertence ao fracasso quando, na realidade, sucesso seria de se esperar na base do trabalho já realizado e da compreensão demonstrada pelo paciente. O que não pode ser esquecido aqui é o fato, fato mesmo, de que a concepção dos pacientes do comportamento e da realização na realidade é excessivamente ilusória. O paciente muito imaturo sente que para ser capaz de viver no mundo da realidade, como o vê, tem de ser tal como concebe que suas imagos sejam. De fato, a investigação dos fenômenos de transferência nos informa que, até onde se sabe, esses pacientes continuam vivendo no mundo de sua infância - de modo que curar-se e tornar-se adulto são alcançados por meio do desejo de ser capaz de fazer o mesmo que os adultos, o que eles não se arriscam a fazer. Na imaginação, é bastante fácil, assim como na análise, mas de resto, a ansiedade é excessivamente intensa.

Outro fenômeno freqüente na transferência é a falta de contato dos pacientes com o analista (imago). Os pacientes, particularmente em período de hostilidade ou de ansiedade, estão num estado de retraimento. Isso não é pouca coisa. Podese perceber que o paciente esconde-se em uma rígida concha de proteção e continua 
sua análise a partir dessa sua posição de segurança contra o analista. A maioria dos pacientes coloca-se a falar sem interrupção como se se esquecessem do analista, mas a interrupção desse fluxo de associações geralmente acarreta raiva ou ansiedade e traz a informação de que o paciente se preocupava com uma possível influência sobre a imago de seus esforços para agradar ou apaziguar a raiva dessa mesma imago. Essa tendência também se encontra em outros tipos de pacientes, embora em grau ou duração menor do que em nossos pacientes. De fato, esse modo de transferência é típico e varia em grau em função da quantidade de narcisismo (rigidez). Pode-se confirmar que essa exclusão do analista envolve muitos fatores, sendo um dos mais impressionantes a remoção pelo paciente de si mesmo de uma figura parental hostil, crítica e ridicularizada. Tem-se o sentimento, a respeito de alguns desses pacientes, de que rastejam até seu buraco onde se trancafiam (estado intra-uterino). $\mathrm{O}$ grau de imaturidade e insegurança que acomete esses pacientes ajuda a entender a natureza intuitiva, arcaica desse mecanismo de defesa.

Nota-se facilmente que a maior parte do trabalho executado por esses pacientes é tendenciosa. Associações intelectuais e superficiais, longas descrições, palavras e frases cuidadosamente escolhidas, arredondadas; uma atitude quieta, contida e forçada, a enunciação de palavras de raiva, ansiedade, amor sem seus conteúdos emocionais, uma insipidez, uma monotonia é o que apresentam, independentemente dos afetos descritos. A ausência de afeto na situação de transferência é característica de muito do trabalho. É claro que esses indivíduos têm o mesmo comportamento em sua vida cotidiana, fora da situação analítica.

Esses pacientes, que chegam para a análise com uma neurose franca na qual a ansiedade é o maior sintoma, desenvolvem já no começo do tratamento um apego violento, apelativo para o analista na sua necessidade imensa de proteção e segurança. Eles se apegam literalmente através de todos os seus sentidos ou órgãos de preensão infantis. No decorrer da análise desses pacientes, que procuram um tratamento sem sentir muita ansiedade por causa do sucesso da repressão, essa ansiedade torna-se patente em razão do estudo de seus mecanismos de defesa, particularmente no campo da transferência, e o quadro descrito acima se inicia. De fato, o tratamento com êxito é caracterizado pela precipitação da ansiedade, no caso de pacientes que conseguiram reprimi-la. Em alguns pacientes, quando a ansiedade é precipitada por uma experiência atual infeliz fora da análise, surge esse mesmo apego. Esses pacientes que não desenvolvem qualquer ansiedade aguda apresentam uma aparência imóvel impassível, às vezes sólida, embora, não raro, descrevam sensações perturbadoras de ansiedade no peito, na barriga, nos genitais e no couro cabeludo (como se fosse arrancado); apenas mais tarde, na análise, é que esses pacientes exprimem seus afetos pela própria voz. O último grupo (impassível) abrange pelo menos $50 \%$ dos pacientes que estou descrevendo como pertencentes ao grupo limítrofe. 


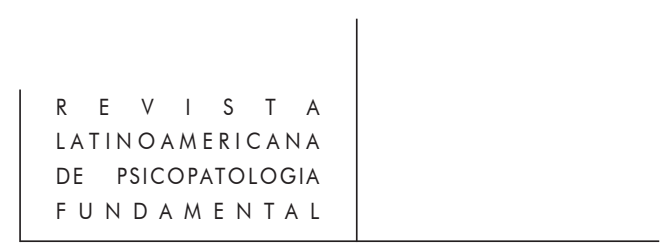

Muitas vezes sentimos falta, a não ser mais tarde na análise, do que nos é familiar como "associações livres" no grupo de pacientes de libido objetal. Pode-se deduzir pelo rumo de minha apresentação que a maior necessidade desses pacientes é a de proteção, isso num grau que supera todas as outras. Não se pode, portanto, esperar "associações livres" do tipo que obtemos com neuróticos menos imaturos. Uma tarefa árdua para esses pacientes é a de liberar sua hostilidade. Como um deles disse: "Já é ruim o bastante do jeito que está; como ficaria se as pessoas pudessem sentir ou ouvir minha hostilidade?” Apenas à medida que a imaturidade, particularmente na transferência, vai melhorando gradativamente e quando a necessidade de proteção diminui, é que se consegue uma imagem da transferência comparável à encontrada nos outros grupos de neuroses. Apenas nesse momento o paciente consegue fazer um uso adequado, apropriado, do material histórico trazido no trabalho analítico; apenas então é que ele entende e incorpora (digere) realmente a importância da maior parte do trabalho (interpretações) realizado concomitantemente com o trabalho quase incessante na relação de transferência. Embora não tenham relação com a transferência, recorre-se freqüentemente às interpretações para dar ao paciente uma oportunidade de exercer seu intelecto e obter alguma satisfação de ego. As interpretações também são feitas no intuito de transmitir conhecimentos ao paciente. $\mathrm{O}$ tempo todo o analista sabe que muito disso será apagado após o paciente alcançar a maturidade, para tornar os efeitos das interpretações sem relação com a transferência menos tendenciosos. Com esse tipo de pacientes é da maior importância que o analista tenha plena consciência de até que ponto o paciente sabe o que sabe. Apenas após a transferência, estabelecida nessa base extremamente imatura, ter sido resolvida é que os apegos parentais do período edipiano, das ameaças de castração, do impulso sexual, de seus prazeres e perigos, e de um punhado de outros fenômenos podem se tornar objeto de explicações capazes de serem entendidas adequadamente. Apenas então é que esses fenômenos adotam seu papel apropriado de fatores de etiologia neurótica nesse grupo limítrofe. Pois a ansiedade que parece ser o motor da formação do sintoma de defesa é anterior, cronologicamente, à ansiedade de castração do grupo das neuroses de transferência; a situação de transferência no nosso grupo reveste, portanto, essas colorações básicas da prima infância. Inicia-se em um período que antecede o desenvolvimento sexual enquanto fator de doenças neuróticas. Ora, isso reaparece mais tarde, acrescendo dificuldades para a criança já sobrecarregada nos seus esforços para lidar com uma insegurança já de grande magnitude.

\section{Conclusão}

As imperfeições deste trabalho são suficientemente evidentes. Uma certa imprecisão é inevitável, por enquanto, em razão do material que esse grupo oferece 
para nossos estudos, que aponta claramente em duas direções, a saber: os neuróticos e os psicóticos. Seria preciso muito mais tempo e análise para avaliar os fenômenos bastante escuros que esses pacientes apresentam.

Parece ser legítimo alegar que eles formam um grupo em si, designado como limítrofe. Baseados nessa alegação, encontramos nesse grupo características que separam esses pacientes do tipo comum de psiconeuróticos. São essas características que tentei descrever. Este trabalho se preocupou com uma descrição a partir de duas perspectivas: a primeira, histórica, tal como dada pelo paciente e desenvolvida em seguida no decorrer do tratamento e do estudo, e, a segunda, o estudo dessas características assim como operam na situação de transferência.

Essa última abordagem oferece oportunidades para estudar esses traços de caráter que apresentam muitas vantagens. Pode-se ter uma oportunidade de vê-los mobilizados pela situação de transferência, formando uma neurose em "miniatura", podendo ser seus elementos mais facilmente estudados por dizerem respeito ao paciente e à imago (analista); além do mais, exatamente como no caso da situação de transferência dos psiconeuróticos, isso indica ao analista quais medidas terapêuticas adotar.

Uma vez que nesse grupo limítrofe o narcisismo é o material subjacente a partir do qual se originam os sintomas (defesa) na base das necessidades (ansiedade), medidas psicanalíticas são instituídas exatamente como no caso dos psiconeuróticos, para os quais a ansiedade surge com os impulsos psicossexuais. Entretanto, no nosso grupo, o narcisismo é que é a fonte da ansiedade. Embora há muito estejamos familiarizados com o narcisismo, quando está presente em grandes quantidades, como nos fenômenos exibidos pelos pacientes, nenhuma abordagem direta em ampla escala foi tentada. Este é o objetivo deste trabalho: mostrar que o narcisismo é sujeito não apenas à investigação como à terapia psicanalítica.

Não resta dúvida de que esses pacientes não são adequadamente tratados por métodos que conferem um certo sucesso com os psiconeuróticos comuns. A mesma técnica psicanalítica, com as variações acima indicadas pode ser aplicada nos casos do grupo limítrofe só que, embora os cuidados com e o tratamento dos impulsos psicossexuais perturbados estejam incluídos, também há de se ter uma atenção com e um tratamento do narcisismo perturbado.

Como no caso dos psiconeuróticos, nesse grupo limítrofe, por menor que seja a parte do ego saudável em funcionamento que não esteja envolvida na doença, ela será utilizada pelo analista em seus esforços para obter resultados. Está claro, no entanto, a partir da descrição desse grupo limítrofe, que grande parte do ego que funciona está envolvida na doença, uma parte maior do que no grupo de transferência. Este é um traço relevante desse grupo limítrofe que torna a terapia mais difícil e o prognóstico mais grave do que no caso dos psiconeuróticos. 


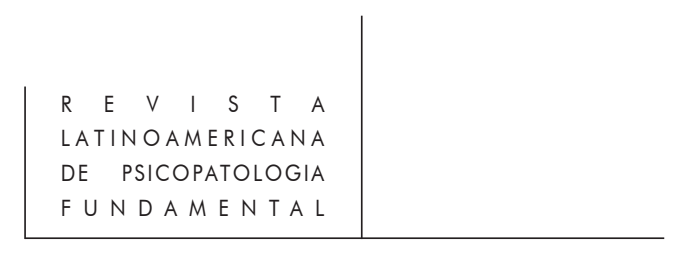

Apenas nesse contexto é que o que chamei acima de modificações na aplicação da terapia psicanalítica é indicado. Na verdade, não há mudança; a experiência ensinou-me várias coisas quanto a essa situação de transferência dependente com apego extremo e desesperado. Esses pacientes precisam de um tratamento de apoio muito maior do que o tipo comum do neurótico. Entre os pacientes desse grupo limítrofe, tanto os que já vêm com neuroses agudas, principalmente depressão e ansiedade generalizada, como os que desenvolvem transtornos no decorrer da terapia, caso mais comum, encontramos pessoas muito doentes, muito mais do que no grupo dos psiconeuróticos. Este último grupo apresenta regularmente um quadro menos grave. De modo que, como na fisioterapia, os mais doentes são amparados, por assim dizer, por todo tipo de tratamento de apoio enquanto as medidas medicinais são aplicadas e as medidas radicais adiadas até que a força de resistência do paciente seja suficiente. Em nosso campo, também longos períodos de tratamento de apoio são um preparo essencial para o momento em que a técnica psicanalítica poderá ser aplicada. Uma vez que esses pacientes são gravemente doentes e que o trabalho com relação de transferência, que age como um agente frustrante, é muito mal tolerado, uma das modificações da técnica consiste numa atenção maior às terapias de apoio. Um foco bastante constante na situação de transferência em detrimento, aparentemente, do material histórico e das interpretações constitui uma segunda modificação. As atitudes afetivamente imaturas, que se manifestam por longos períodos e em grandes quantidades, impossibilitam todo trabalho inteligente, salvo o que o analista pode, por assim dizer, forçar a parte saudável do ego do paciente a realizar para entender suas atitudes dependentes inerentes às suas necessidades narcísicas. De saída, como disse um paciente, esse atravessar "meu caminho" é um processo que incomoda, pois implica frustração por parte dos pacientes, o que eles toleram muito mal. No entanto, um tratamento cuidadoso irá diminuir materialmente o impulso persistente de se apegar e uma certa parte de comportamento intelectual saudável ficará disponível para trabalhar o material histórico e as interpretações.

Entre esses pacientes não raro encontramos aqueles que exigem e buscam "o melhor e o maior" analista como o único capaz de ajudá-los. Sem mais, pode-se pensar que seu amor narcísico influencia tais idéias ou procura. Não é difícil, entretanto, demonstrar que são sentimentos de forte insegurança e inferioridade profundamente reprimidos que fundamentam essa necessidade do "melhor e do maior”. As necessidades narcísicas insaciadas e insaciáveis fundamentam essa demanda.

Palavras-chave: Estados-limites, transtornos borderline, estados limítrofes, psicoterapia. 